\section{Part Special Issue Editorial: The process of OR}

\author{
P Keys and G Midgley* \\ University of Hull, Hull, UK \\ DOI: $10.1057 / \mathrm{sj} /$ jors $/ 2601313$
}

\section{Introduction}

We came to be editing this part special issue of the Journal of the Operational Research Society (JORS) following an invitation from John Ranyard (the previous editor of JORS) who picked up on a point made by Gerald Midgley in a Viewpoint. ${ }^{1}$ Gerald argued that, to be worthy of publication, a practice paper should have some theoretical content-but this does not have to be 'grand' theory, making general claims about human nature or society, just theory about the application of OR methods in interventions. This is essentially theory about the process of OR: about how people can make meaningful value and boundary judgements, negotiate stakeholder participation, deal with power relationships, structure messy situations, engage with multiple viewpoints, address conflict, work on the choice of methods, develop strategies for the implementation of proposed solutions, etc. John asked Gerald if he would like to edit a part special issue on the process of OR, and then Gerald asked Paul Keys to share the honours as Paul had already produced a book on the subject. ${ }^{2}$

\section{Why process?}

When writing reports of OR practice, many practitioners leave out considerations of process issues, or provide only minimal details of them. It is our contention that, in doing so, they are only reporting half the story of their applications - and some of the most important aspects of practice are made invisible. Of course, we should acknowledge that we are by no means the first to make this point. Ron Stansfield $^{3}$ (one of the originators of OR in the Second World War), for instance, wrote about several examples of his own 'biased' reporting of OR interventions, including the following:

'Another example of biased publication happened after I moved in 1944 to the Operational Research Section at RAF Coastal Command. I was asked to look at the way

*Correspondence: G Midgley, Centre for Systems Studies, Business School, University of Hull, Hull, HU6 7RX, UK.

E-mail: G.R.Midgley@hull.ac.uk the Command was training its aircrew to use a new type of bombsight then coming into use. In fact I hardly looked at the techniques of training; the critical problems turned out to be ones of communication within the organization. When I went to look at what was happening, I found-for example-that people doing interacting jobs were isolated at different points along the perimeter track of dispersed airfields. This part of my report, quite unpublishable because it was so bound up with local circumstances and also with high-security information, led to a high-level meeting in the office of the Command's Senior Air Staff Officer, and prompt action. By contrast, no oneas far as I am aware-has ever made use of the material in the published paper deriving from this same study, a paper entitled "The accuracy of wind-finding by the three-course drift method" ...' (Stansfield p 5).

The only difference of opinion we have with Stansfield ${ }^{3}$ is that he assumes (in the above quotation and elsewhere in his paper) that messy human issues are impossible to write up for publication because of their complexity and the fact that each local situation is unique. Nevertheless, he bemoans the fact that this distorts both the public and academic perception of what OR is really about. In our view, it is not only possible, but also essential, to write about these messy human issues - but doing so involves discussing case studies in quite different ways to their usual presentation in OR journals.

\section{Two approaches to discussing process}

We have identified two ways in particular that enable people to deal with process issues in a manner that is meaningful for OR practice. In our view, both are equally valid and useful. The first is to propose a theory or methodological insight of value in understanding a process issue, and then draw upon examples from practice (either from one case study or several) to support the arguments being constructed. The second way is to make the primary focus a rich, detailed narrative about an application of OR, and then write about theory within this. A typical example of the latter is when the practitioner is making choices about the 
design of methods, and a particular theory about the potential consequences of applying a given approach informs decision-making. Here, the methodological or theoretical ideas can be introduced as part of the narrative. Also, if novel insights can be derived from reflection on the case study, these might be used to propose new theoretical ideas of use to other practitioners.

\section{The papers in this part special issue}

In this issue of JORS you will find four papers which exemplify the first of the above approaches: use of case study data to support methodological and theoretical arguments. Essentially, their main narratives are about ideas of use to OR practitioners in dealing with process issues, and material from applications (or the analysis of actual situations) is provided in support of the authors' arguments. Below, we review each of the four papers. We hope you will agree with us that taking this kind of approach to understanding process issues can be of great value to practitioners wanting to enhance their OR practice. Then we reflect on why it is less common to find a rich narrative approach in the OR literature, and we suggest how journals can encourage the submission of more papers along these lines.

The first paper in this part special issue is by Ann Taket. She argues that the theory of deconstruction (originally proposed by Derrida ${ }^{4}$ ) can be useful for OR facilitators because it makes clear that a 'unified' or 'internally consistent' discourse maintains its coherence at the expense of other ways of thinking that are, in some sense, opposite to it. Therefore, by looking for what is suppressed in discourses, new understandings of problem situations (and how to address them) may emerge. Interestingly, deconstruction is having an impact in a variety of disciplines concerned with intervention, including family therapy ${ }^{5}$ and systems thinking, ${ }^{6}$ so Ann's introduction of these ideas to an OR audience is most timely.

Ann also argues in her paper that theories from the tradition of 're-evaluation counselling, 7 or 'co-counselling' can be of value in understanding how practitioners can deal with emotional dynamics during engagements with participants in OR projects. Arguably, because of the historical focus of OR on the discourse of rational analysis (which focuses attention on the relatively 'detached' consideration of issues, rather than expressions of emotion), the handling of emotional dynamics has been neglected over the years. Of course, anybody involved in facilitating debate as part of their practice will tell you that emotional dynamics do not disappear when we engage in OR. Therefore, theories that can help us address them - such as the ones from cocounselling proposed by Ann - are very welcome.

The second paper, by Zhichang Zhu, discusses the Chinese Wuli-Shili-Renli (WSR) methodology ${ }^{8}$ that has been developed following 50 years of reflection on OR projects. WSR draws for inspiration on ancient Chinese philosophy as well as modern understandings of systems thinking and $\mathrm{OR},{ }^{9}$ and focuses on the interplay between 'relations with the world', 'relations with the mind' and 'relations with others' (see the paper itself for more details). Given this tripartite classification, the methodology inevitably views process issues as integral to all OR projects - they are not merely an add-on concern.

Zhichang talks in terms of enhancing the 'user-friendliness' of OR, but is critical of methodologies that construct new languages of user participation that are substantially different from the normal languages known and used by managers and decision makers. He argues that new methodological languages can distance the practitioner from users of OR, which is counter-productive in terms of the very user-friendliness that the languages are designed to promote. WSR, in contrast, asks practitioners to view OR as enhancing the management process, which means engaging with the languages of those involved in that process rather than imposing new languages as largely separate discourses. In the course of developing his argument, Zhichang illustrates what it means to him to conduct user-friendly OR by describing his involvement in a large pilot project introducing IT into Chinese superstores.

The third paper, by Leroy White, focuses on the increasing interest being shown by policy makers in involving large groups of people (often including diverse stakeholders) in planning and decision making processes. Leroy's basic argument is that 'size matters': facilitating large groups (often running into hundreds of participants) requires very different methods to those usually used by OR practitioners who work with relatively small numbers.

Leroy discusses why OR practitioners should take the issue of working with large groups seriously, and presents two case studies from his own practice (using Open Space Technology ${ }^{10}$ and Team Syntegrity ${ }^{11}$ ) to illustrate how large-scale participation can be facilitated. In our view, this paper is useful because it brings to the attention of OR practitioners a set of methodologies developed by writers who are clearly doing research of direct relevance to us, but whose work is not yet widely used in our community.

The final paper, by Franz Liebl, draws upon a wide range of empirical and theoretical research from the social sciences to describe the nature of complex societal problems. The focus is on how issues emerge and develop in often unpredictable ways. Franz produces a fascinating analysis of the factors impacting on the trajectories of societal problems. He then systematically examines the implications of his analysis for the practice of OR, using case study data to illustrate the points he is making.

\section{Rich narratives}

Now, we believe that the approach taken by all four of the authors writing for this part special issue-supporting a 
theoretical or methodological argument with case study data-is extremely valuable to practitioners. However, rich narratives of practice, drawing upon theory along the way, can also be valuable - but they are rarely found in OR journals. We will end our Editorial with some reflections on why this might be the case.

Essentially, we believe that practitioners wishing to write rich narratives are faced with an insurmountable obstacle: the five- or six-thousand word limit usually used by OR journals. While most editors are flexible on this up to a point, in our view a great deal more space is needed for an adequate presentation of a rich narrative. To illustrate, one of us has produced a book ${ }^{12}$ that includes three narrative case studies (plus one written as an illustration of theory), and the narratives vary between 8500 and 12600 words. In these, much of the description of theory is abbreviated because it is presented in full in other chapters, so if the cases were to be converted into stand alone journal papers they would almost certainly be between 10000 and 15000 words long. This is much longer than most OR journals are currently prepared to consider, except occasionally. Long papers do sometimes get accepted (Franz Liebl's in this part special issue being an example), but they are very much the exception rather than the rule.

We therefore want to make the case for a significant shift in the editorial policies of most OR journals, making available considerably more space for rich descriptions of applications - as well as methodological and theoretical papers illustrated with examples from practice (like the ones in this part special issue). Some might complain that this will mean less space for the more traditional, shorter papers presenting novel techniques and mathematical innovations. Of course this is the case, but we argue that, given what we said earlier about the importance of explicitly addressing process issues in descriptions of practice, the sacrifice is worth it. It will restore some balance to presentations of OR applications, correcting the erroneous impression given by a large number of purely technical papers (and bemoaned by Ron Stansfield, ${ }^{3}$ Colin Eden ${ }^{13}$ and others) that OR is hardly concerned with process at all.

\section{Editors' note}

The recommended limit on size for papers to be published in this journal is 6000 words. However, we are always prepared to be flexible with this limit if and when the situation warrants it.

\section{References}

1 Midgley G (1998). Theory and practice in operational research. J Opl Res Soc 49: 1219-1220.

2 Keys P (ed) (1995). Understanding the Process of Operational Research: Collected Readings. Wiley: Chichester.

3 Stansfield RG (1981). Operational research: dying to live? Paper presented (and text of talk distributed) at the Operational Research Society Annual Conference held at the University of Sussex, 8-11 September 1981.

4 Derrida J (1978). Writing and Difference. Routledge \& Kegan Paul: London.

5 Larner G (1995). The real as illusion: deconstructing power in family therapy. J Family Therapy 17: 191-217.

6 Midgley G and Ochoa-Arias AE (2001). Unfolding a theory of systemic intervention. System Practice Action Res 14: 615-650.

7 Jackins H (1990) The fundamental nature of re-evaluation counseling. Present Time 21: 3-13.

$8 \mathrm{Gu}$ J and Zhu Z (2000). Knowing Wuli, sensing Shili, caring for Renli: methodology of the WSR approach. System Practice Action Res 13: 11-20.

9 Zhu Z (2000). Dealing with a differentiated whole: the philosophy of the WSR approach. System Practice Action Res 13: 21-57.

10 Owen H (1997). Open Space Technology: A User's Guide, 2nd edn. Berrett-Koehler: San Francisco.

11 Beer S (1994). Beyond Dispute. Wiley: Chichester.

12 Midgley G (2000). Systemic Intervention: Philosophy, Methodology, and Practice. Kluwer/Plenum: New York.

13 Eden C (1982). Problem construction and the influence of OR. Interfaces 12: 50-60. 